\title{
Phosphino-amine ( $P N)$ ligands for rapid catalyst discovery in ruthenium-catalyzed hydrogen-borrowing alkylation of anilines: a proof of principle
}

\author{
Lewis Marc Broomfield, Yichen Wu, Eddy Martin, Alexandr Shafir* \\ a Institute of Chemical Research of Catalonia (ICIQ), Av. Països Catalans 16, 43007, Tarragona, Spain. \\ Fax: (+34) 977-920-222 \\ e-mail: ashafir@iciq.es
}

Received: ((will be filled in by the editorial staff))

Supporting information for this article is available on the WWW under http://dx.doi.org/10.1002/adsc.201\#\#\#\#\#\#.

\begin{abstract}
.
A general synthetic protocol for the synthesis of simple phosphinoamine (PN) ligands is described with 19 ligands being isolated in good yields. High-throughput ligand screening uncovered the success of two of these ligands for aromatic-amine alkylations via ruthenium-catalyzed hydrogen borrowing reactions. The combination of $N, N^{\prime}$-bis(diphenylphosphino)- $N, N^{\prime}$ dimethylpropylenediamine with a ruthenium(II) source and potassium hydroxide $(15 \mathrm{~mol} \%)$ is the optimal system for selective monobenzylations of aromatic amines (method A). Over $70 \%$ isolated yields have been achieved for the formation of 14 secondary aromatic amines under mild reaction conditions $\left(120^{\circ} \mathrm{C}\right.$ and 1.05 equivalents of benzyl alcohol).
\end{abstract}

On the other hand, $N, N$-bis(diphenylphosphino)-isopropylamine was the ligand utilized for both selective monomethylation and monoethylation reactions of aromatic amines (method B). Here the alcohol is charged as both the reaction medium and substrate and 9 examples are disclosed with all isolated yields exceeding $70 \%$. These methods have been applied to the synthesis of important synthetic building blocks based on aminoferrocene.

Keywords: alkylation; hydrogen borrowing; ruthenium catalysis; PN ligands; high throughput screening

\section{Introduction}

A variety of catalytic processes utilize phosphine ligands to moderate the reactivity of catalytic metal centers. ${ }^{[1]}$ Despite doing this job very effectively, the synthesis of these ligands however can be work consuming and often delicate, due to the sensitive nature of the reagents applied (Scheme 1, a). Indeed this aspect causes a bottle neck when requiring speedy structural modifications for rapid reaction discovery and optimization. In this context, phosphino amines, referred here as PN ligands, offer a valuable scaffold for generating structural ligand diversity for process optimization. Contrary to their triorganophosphine counterparts, these PN derivatives are obtainable in a relatively simple single-step procedure by condensing an amine with a chlorophosphine (Scheme 1, reaction B). ${ }^{[2]}$ This synthetic method is versatile and the abundance of commercial amines allows ample ligand sets to be swiftly generated for rapid parallel screening. ${ }^{[3,4]}$

Indeed, ligands based on the PN scaffold have been widely used in catalytic processes, including nitrile hydrations, ${ }^{[5]}$ transfer hydrogenations of acetophenone derivatives ${ }^{[6]}$ and cross-coupling reactions with gold. ${ }^{[7]}$ Many enantioselective catalytic processes also benefit from the modular chiral P-N systems pioneered by Alexakis and Feringa. ${ }^{[8]}$ In bulk processes, the use of PNP ligands is the basis for industrial chromium-based production of 1-hexene and, more recently, 1-octene from ethene. ${ }^{[2 a-h]}$

$$
\begin{aligned}
& \text { a) representative synthesis of a bis-phosphine } \\
& \text { - pyrophoric reagents }
\end{aligned}
$$

b) phosphino-amine (PNRNP type) ligand synthesis

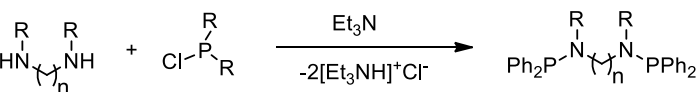

$$
\begin{aligned}
& \text { + many commercially avaliable amines + air stable in solid state } \\
& \text { + relatively easy to handle + easy to modulate structure }
\end{aligned}
$$

Scheme 1. A comparison of synthetic approach towards bisphosphines with bis-phosphino-amines. ${ }^{[2]}$

Wide-scope screening of PN ligand sets by taking advantage of their simplistic synthesis however is scarce. Yet, this feature has been effectively exploited by Wasserscheid at al. ${ }^{[2 \mathrm{~d}]}$ in ethylene oligomerization. This study found that the selectivity (in particular 1octene vs. 1-hexene) could be tuned by altering the steric bulk on the central nitrogen atom of a PNP ligand. Thus, we wondered to what extent the facile generation of phosphino amines can be used to develop and optimize other catalytic processes. In light of the structural (albeit not electronic) similarity between linear disphosphines and bis-phosphino amines built with linear aliphatic diamines, we chose 
$\mathrm{Ru}(\mathrm{II})$-catalyzed $\mathrm{H}_{2}$-borrowing reactions, more specifically alkylations of amines by alcohols, as a possible candidate for the rapid process optimization. This choice of process was strongly influenced by the fact that bisphosphines are commonly utilized to modulate metal centers in these processes (vide infra). In addition, such catalytic protocols are in many ways preferable to the more classical nucleophilic substitution approaches, which typically use alkyl halides as alkylating agents. ${ }^{[9]}$ Two clear advantages of using $\mathrm{H}_{2}$-borrowing catalysts to perform aminealkylation reactions are superior reaction control and the fact that the toxicity of alcohols, employed as alkylating agents, tends to be lower than of the corresponding alkyl halide. ${ }^{[10-12]}$ Therefore, amine alkylation reactions by alcohols complement perfectly the reductive amination of aldehydes, with both methods affording the same product. A basic sequence of this reaction is outlined in Scheme 2 and operates by metal-catalyzed dehydrogenation of an alcohol $\mathrm{A}$ to form an aldehyde $\mathrm{B}$. Once the imine $\mathrm{C}$ is formed through the condensation with an amine, the borrowed hydrogen is then returned at the $\mathrm{C}=\mathrm{N}$ bond to yield the target secondary amine $D^{[13]}$ Significantly water is the only reaction byproduct in this process.

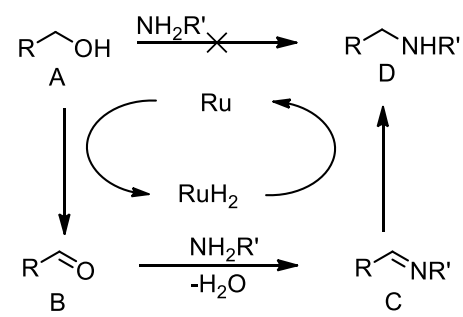

Scheme 2. Hydrogen borrowing strategy in the alkylation of amines by alcohols.

Regarding effective catalytic systems for such transformations, Williams has developed various by regulating the activity of $\left[\mathrm{RuCl}_{2}(p \text {-cymene })\right]_{2}$ with bisphosphine ligands (DPPF and DPEphos are two prominent ligands used, Figure 1). The resulting catalytic systems were found to effectively catalyze a number of amine alkylation reactions under relatively mild reaction conditions. ${ }^{[14]}$ Additionally important pharmaceuticals have been isolated in good yields using this combination (Piribedil, 87\%, Tripelennamine, $75 \%$ and Chlorpheniramine, $81 \%$ are just 3 examples). ${ }^{[14 \mathrm{~b}, 14 \mathrm{c}]}$ Along the same lines, Deutsch et al. ${ }^{[15]}$ recently applied Ru(II) complexes of DPEphos for alkylation protocols of ammonia by alcohols. Yields of above $90 \%$ to the desired primary amines were achievable in some cases. Importantly, in addition to DPEphos, several commercial bisphosphines, bridged by linear alkyl chains (Figure 1 ), were also operative ligands for this reaction. Of these, particularly effective was DPPB, which gave cyclohexanamine in $94 \%$ yield. Worth mentioning is that increasing this carbon backbone by one methylene unit to a pentylene bridge inflicts a drastic drop in product yield to just $26 \%$. This difference highlights the importance of testing many ligands with slight structural modifications in catalysis. Finally, Wass et al..$^{[16]}$ used a catalytic system comprising of $\left[\mathrm{RuCl}_{2}(p \text {-cymene })\right]_{2} / \mathrm{DPPM} / \mathrm{NaOEt}$ in selective ethanol upgrade (Guebert process). An impressive $23 \%$ yield with $89 \%$ selectivity for $n$ butanol was achieved by the in-situ system. It was suggested the small bite angle $\left(\beta_{\mathrm{n}}\right)$ of DPPM aided the superlative selectivity achieved by this homogeneous $\mathrm{Ru}(\mathrm{II})$ catalyst.

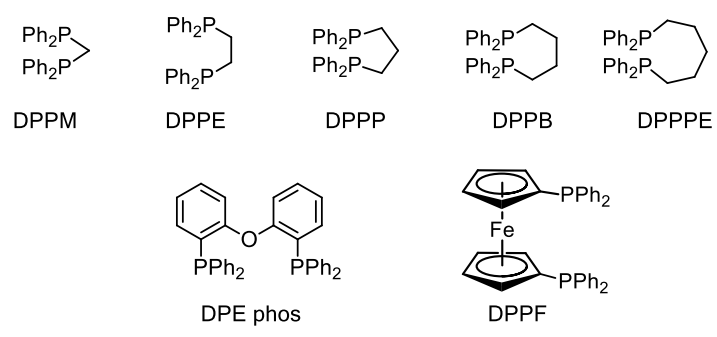

Figure 1. Selected examples of commercial bisphosphines used as ligands in $\mathrm{Ru}(\mathrm{II})$-catalyzed $\mathrm{H}_{2}$-borrowing reactions.

Considering these factors we decided to acquire a robust synthetic procedure for PN ligands in order to rapidly generate an initial ligand library. With this ligand library in hand, we have tested its aptitude in modulating $\mathrm{Ru}(\mathrm{II})$-catalyzed $\mathrm{H}_{2}$-borrowing alkylations of aromatic amines. Herein, we report our findings concerning this research.

\section{Results and Discussion}

\section{Ligand syntheses}

At the outset, three simple families of PN ligands would be rapidly generated, allowing us to cover a range of complex structures. The first two families would derive from primary amines that, depending on the number of equivalents of chlorophosphine charged, would give either a "PNP" or a "PNH" system (type $\mathbf{1}$ and 2). In addition, the third PNR family is obtainable using secondary amine scaffolds (type 3). Furthermore, within each family, both mono- and diamines can be employed.

Thus, all ligands (1-3) were synthesized by condensing a chlorophosphine $\mathrm{R}_{2} \mathrm{PCl}(\mathrm{R}=\mathrm{Ph}$ or $i \mathrm{Pr})$ with the corresponding amine in the presence of $\mathrm{Et}_{3} \mathrm{~N}$ (Scheme 3). Given the size of the intended ligand pool, the published condensation procedure ${ }^{[2 \mathrm{~g}]}$ was revised in order to minimize the quantities of chlorophosphine and base required, therefore simplifying the time-intensive purification protocol. The ${ }^{31} \mathrm{P}$ NMR proved an invaluable handle for monitoring progress of the reaction. Under these revised conditions, the pure products are produced in good yields (66-91\%) upon extraction with toluene and a subsequent washing of the solids with 
acetonitrile. Alternatively, for oily products (as for $\mathbf{2 c}$, $\mathbf{3 b}, 3 \mathbf{e}, \mathbf{3 f}$ ) a ligand of sufficient purity is obtained by extraction with hexane. For $\mathbf{3 b}$, prepared from $N, N^{\prime}-$ dimethylpropylenediamine, analytically pure samples were achieved by an additional washing with degassed ethanol. While both 1,2-ethylenediamine and 1,3-propylenediamine reacted readily with 4 equivalents of diphenylchlorophosphine, to afford the corresponding bis-PNP systems (1e and 1f), in the case of the more constrained trans-1,2cyclohexanediamine the reaction stopped at three phosphine groups. The solid-state structure of the resulting $\mathbf{2 b}$ placed the remaining $\mathrm{NH}$ deep within a pocket formed by the surrounding residues; attempts to activate this $\mathrm{NH}$ group, including the use of $n \mathrm{BuLi}$, were futile.

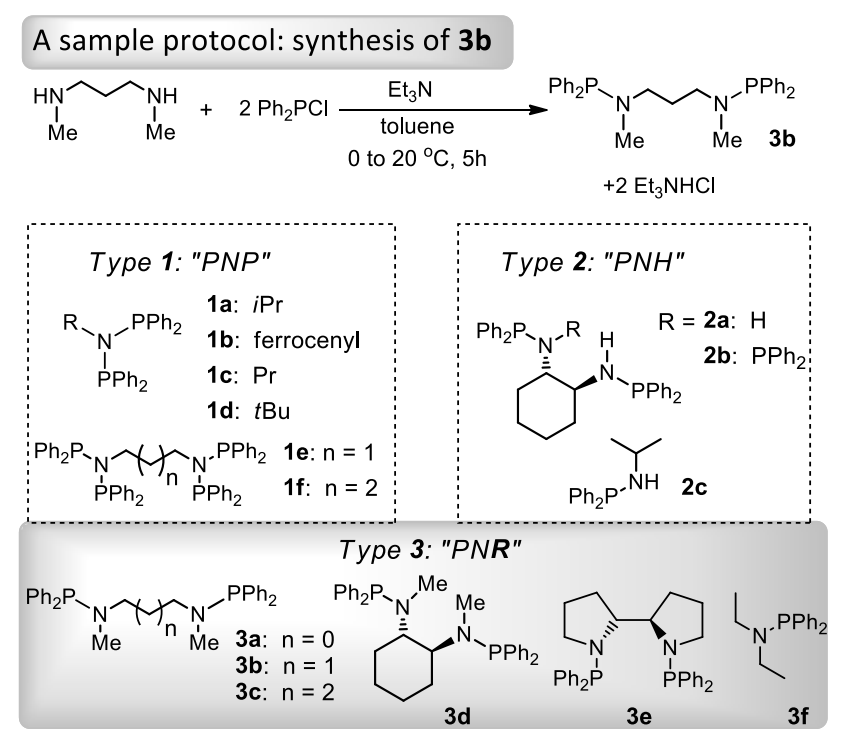

Scheme 3. The generated PN-ligand library.

For $\mathbf{2 b}$, the ${ }^{31} \mathrm{P}-\mathrm{NMR}$ spectrum contains a singlet and two doublets, the latter for the diastereotopic PNP phosphorous atoms. ${ }^{[17]}$ Interestingly, while each of the $N$-bound ring $\mathrm{C}$ atoms was expected to couple to all three $\mathrm{P}$ atoms, the two ${ }^{13} \mathrm{C}-\mathrm{NMR}$ resonances appear as doublet of doublets, indicating coupling to only two $\mathrm{P}$ in each case. Selective decoupling experiments (see Supporting Info) reveal that one of the two P of the PNP unit does not couple with these $\mathrm{C}$ nuclei, likely due to the $\mathrm{P}$ lone pair (lp) oriented nearly antiperiplanar $\left(168^{\circ}\right.$ in solid state) to the N-C bond in the lp-P-N-C system (Figure 2). ${ }^{[18]}$

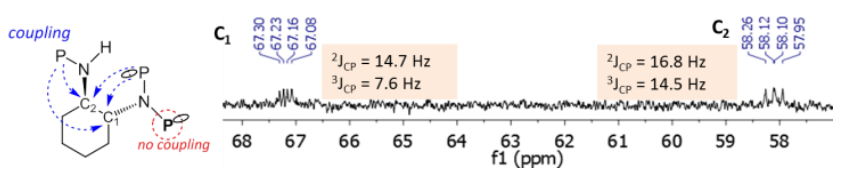

Figure 2. "Isolation" of one of the PNP phosphori from the $\mathrm{C}_{1}$ and $\mathrm{C}_{2}$ spin systems; section of the corresponding ${ }^{13} \mathrm{C}$ NMR spectrum is shown.

\section{Catalytic activity}

The PN ligands generated were then tested in the model Ru-catalyzed $N$-benzylation of aniline $\left(\mathrm{PhNH}_{2}\right)$ with benzyl alcohol $(\mathrm{BnOH})$. The initial reaction conditions, chosen based on recent work by Williams et al. ${ }^{[14 \mathrm{~b}, 14 \mathrm{c}, 19]}$ and our own preliminary tests, consisted in exposing $\mathrm{PhNH}_{2}$ and a slight excess of $\mathrm{BnOH}$ (1.05 equiv) to $\left[\mathrm{RuCl}_{2}(p \text {-cymene) }]_{2}\right.$ (at 1.25 $\mathrm{mol} \% \mathrm{Ru})$ and $\mathrm{KOH}(15 \mathrm{~mol} \%)$ in toluene at $150{ }^{\circ} \mathrm{C}$. As a benchmark, the coupling in the absence of an additional ligand led to an $87 \%$ consumption of $\mathrm{PhNH}_{2}$ after $12 \mathrm{~h}$ and the formation of a roughly equimolar mixture of the targeted benzylaniline (49\%) and the corresponding imine (34\%).

While no benzylamide (another potential side product) could be detected, this outcome signaled a difficulty in the last imine rehydrogenation step under these "ligand-free" conditions. As seen in Figure 3, the introduction of any of the PN ligands (at $2 \mathrm{P} / \mathrm{Ru}$ loading) from the preliminary library increased the selectivity towards $N$-benzylaniline. Nevertheless, for the PNP and PNH ligand families (1a-f, 2a-c), this improvement came at a cost of the reaction rate. However, competitive rates were recovered using the bridged PNR ligands 3a-e. In particular, to our delight the use of $\mathbf{3 b}$, comprising two $\mathrm{Ph}_{2} \mathrm{PN}(\mathrm{Me})$ moieties bridged by a propylene linker, afforded $N$ benzylaniline in a $94 \%$ yield, with only traces of the imine being detected by GC. The privileged size of the three-carbon tether in $\mathbf{3 b}$ is evidenced by the somewhat inferior catalytic performance of the twoand four-carbon bridged analogs 3a and 3c. Moreover, the poor performance achieved using the monophosphine 3e (44\% yield, 57\% selectivity) indicates the importance of a tethered system.

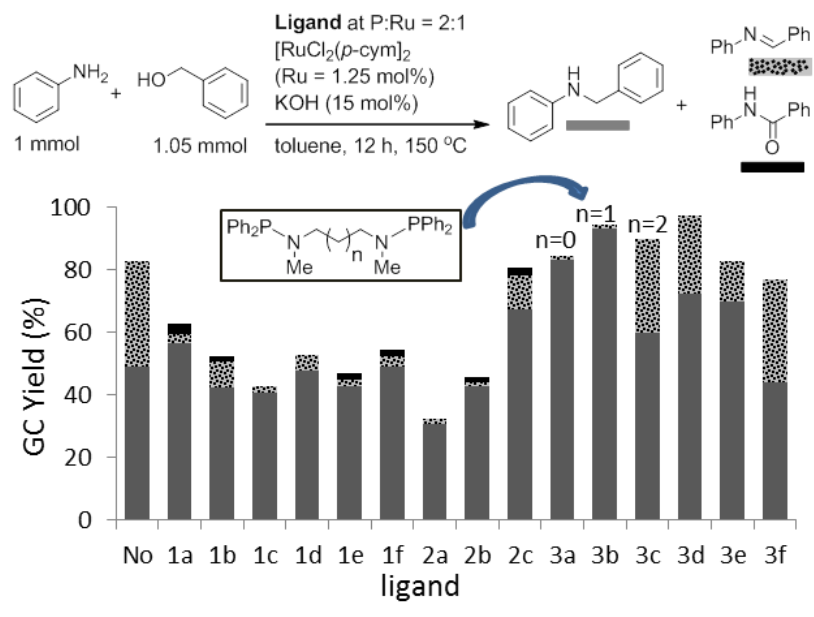

Figure 3. Screening of the PN library in the $\mathrm{Ru}(\mathrm{II})$ catalyzed $N$-benzylation of $\mathrm{PhNH}_{2}$ by BnOH. \%GC yields $v s$. mesitylene (average from at least two separate runs).

Additional structure-activity insights were gained by testing further modifications of the "winning" propylene-bridged system 3b (Figure 4). Replacing the $\mathrm{Ph}_{2} \mathrm{P}$ groups with more electron-donating $i \mathrm{Pr}_{2} \mathrm{P}$ (L1) led to a drop in catalyst selectivity as evidenced 
by the formation of $25 \%$ of imine side product. Replacing the central $\mathrm{CH}_{2}$ group with a $\mathrm{CMe}_{2}$ unit (L2 and L3) led to relatively poor catalytic performance, lending evidence to the key role played by the hydrogens of the central propylene $\mathrm{CH}_{2}$ group in 3b (vide infra). Finally, the superior catalyst performance of $\mathbf{3 b}$ appears to be strongly correlated with the presence of the $N \mathrm{Me}$ linkers as replacing these with either oxygen $(\mathbf{L 4})$ or $\mathrm{CH}_{2}$ units (DPPPE, Figure 6) led to systems with lower catalytic activities.

Additional exploration (Table 1) showed that the process could be further improved by lowering the temperature to $120{ }^{\circ} \mathrm{C}$, whereby the use of $1.25 \mathrm{~mol} \%$ of the 1:1 Ru:3b catalyst system now led to quantitative formation of $N$-benzylaniline (compare entries 1 and 2; see Supporting Info for the GC trace). Nevertheless, inferior results were obtained at $110^{\circ} \mathrm{C}$ (entry 3) or at other ligand-to-metal ratios (entries 4 and 5). Notably, none of the benzyl benzoate side product is formed at these lower temperatures.

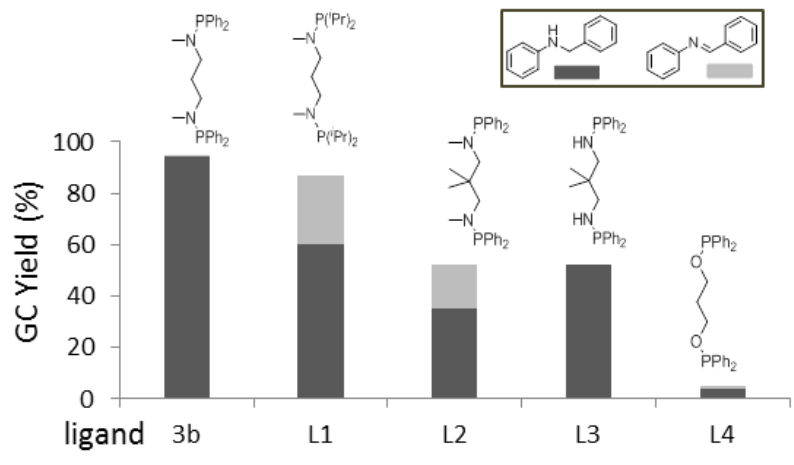

Figure 4. Performance survey of additional propylenediamine-bridged systems; conditions as in Fig. 3.

The efficiency of the reaction also depended on the seal created by the septum, as the use of older septa sometimes led to the appearance of the imine sideproduct. Indeed, piercing the septum or removing it altogether (open reflux) led to the formation of $42 \%$ and $71 \%$ of the imine, respectively (Table 1, entries 6 and 7). These observations indicate the importance of the equilibrium associated with the ruthenium dihydride species (eq 1), given its role in the $\left[\mathrm{H}_{2}\right]$ drop in non-sealed system.

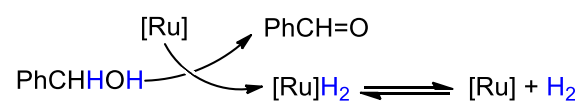

Of the bases tested, potassium hydroxide led to the most effective catalyst system (see Supporting Info for base screening). In this case, the catalytic activity showed a sharp dependency on $\mathrm{KOH}$ loading; dipping at approx. $2 \mathrm{~mol} \%$ and then rising sharply at base loadings of 5-10\% (Figure 5). Although $6 \mathrm{~h}$ was sufficient to obtain full conversion, a 12-hour process was chosen for robustness. We note that under these optimized reaction conditions, $\mathbf{3 b}$ outperforms a number of commercially available bisphosphine ligands (Figure 6).

Table 1. Selected optimization experiments of the $\mathrm{Ru}(\mathrm{II})$ catalyzed benzylation of aniline.

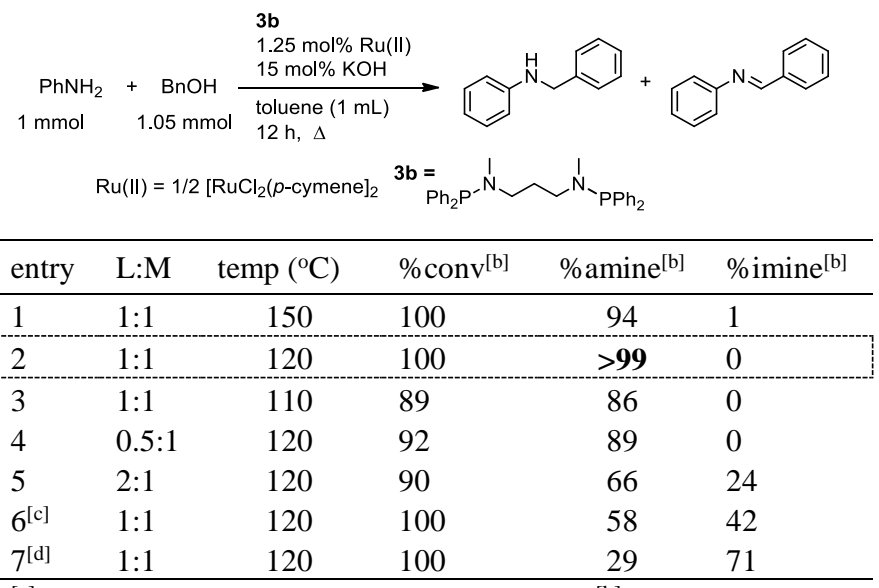

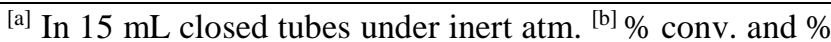
yields (average from at least two separate runs) by GC vs. mesitylene as int. standard. ${ }^{[c]}$ Septum was pierced with a needle. ${ }^{[d]}$ Open reactor under reflux.

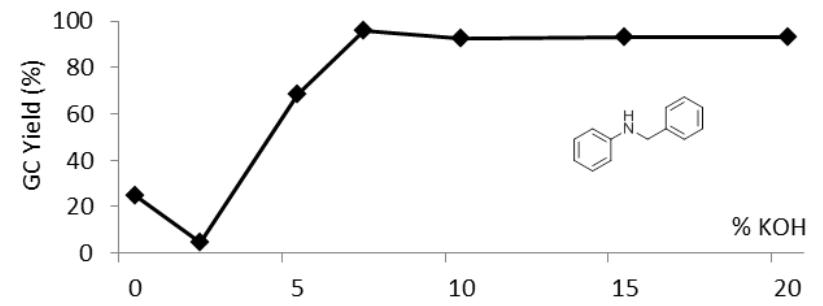

Figure 5. Catalytic activity of $\mathbf{3 b} / \mathrm{Ru}(\mathrm{II})$ vs $\% \mathrm{KOH}$ (coupling $\mathrm{PhNH}_{2}+\mathrm{BnOH}$ ). Rest of conditions as in run 4 in Table 1.

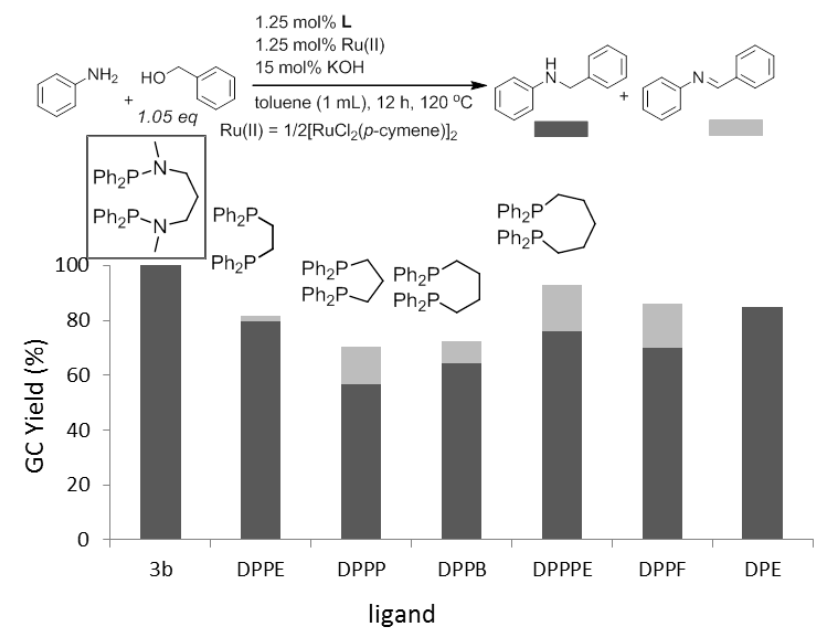

Figure 6. Comparison of $\mathbf{3 b}$ with a selection of commercially available bis-phosphines. 


\section{Substrate scope}

Given the synthetic potential of $N$-alkylations of amines using $\mathrm{H}_{2}$-autotransfer in the pharmaceutical industry, ${ }^{[12 \mathrm{j}, \mathrm{k}, 14 \mathrm{~b}, \mathrm{c}, 20]}$ the substrate scope for this process was explored using the propylenediaminebased ligand $\mathbf{3 b}$ under the optimized conditions. Indeed, several para- and meta-functionalized anilines were successfully $N$-benzylated using $\mathrm{BnOH}$. For example, $N$-benzyl-4-chloroaniline was isolated in $92 \%$ yield after $12 \mathrm{~h}$ (Table 2, Ae). In contrast, anilines with either $\mathrm{CN}$ or $\mathrm{CF}_{3}$ in para proved problematic (Table 2, Af and Ag). ${ }^{21}$ The coupling of ortho-substituent anilines and alkyl amines were also more sluggish as exemplified by the $N$-benzylation of $o$-toluidine (42\% after $12 \mathrm{~h}$ ) and $n$-pentylamine (13\% after $12 \mathrm{~h})$.

In terms of the alkylating agent, a range of substituted benzyl alcohols were successfully coupled with aniline (Table 2, products $\mathbf{A a}$ and $\mathbf{A j - A n}$ ). An interesting case was found for $p$-bromobenzyl alcohol, which initially afforded only a modest yield (40\%) of the target $N$-(4-bromobenzyl)aniline (Am). However, a series of control experiments led to a modified protocol, under which the $p-\mathrm{Cl}$ and $p$-Brbenzylalcohols were used as substrates in the presence of $10 \mathrm{~mol} \%$ of $\mathrm{BnOH}$ as a booster. The finding stems from efforts to establish whether the poor performance of the halogen substituted benzyl alcohols is due to catalyst deactivation by these substrates. Thus, for the control aniline benzylation with $\mathrm{BnOH}$ in the presence of $p$-bromobenzyl alcohol, not only was the presence of this additive well tolerated, but the latter was also found to undergo efficient coupling with aniline. Thus it would appear that $\mathrm{BnOH}$ either prevents the catalyst deactivation event, or is able to restore the catalytic activity, particularly for the imine hydrogenation step. This modification led to respectable yields of the target $N$ benzylated products Al (74\%) and Am (71\%). Conversely, although the coupling of non-benzylic alcohols with aniline was possible, (Table 2), products Ao and Ap), the yields did not exceed $60 \%$.

A solvent screen, conducted as part of the reaction optimization with $\mathbf{3 b}$, revealed that the use of $\mathrm{MeOH}$ as solvent led to selective aniline mono-methylation, with $N$-methylaniline detected in $57 \%$ yield. Encouraged by this result, the initial PN-ligand library was re-examined seeking to further improve this highly-selective methylation reaction. Heating a $\mathrm{MeOH}$ solution of aniline ( $1 \mathrm{mmol}$ in $1 \mathrm{~mL})$ in the presence of $\left[\mathrm{RuCl}_{2}(p \text {-cymene })\right]_{2} \quad(\mathrm{Ru}(\mathrm{II})=1.25$ $\mathrm{mol} \%$ ) and $\mathrm{K}_{2} \mathrm{CO}_{3}(15 \mathrm{~mol} \%)$ at $120{ }^{\circ} \mathrm{C}$ for $12 \mathrm{~h}$ under "ligand-free" conditions only afforded $35 \%$ of $N$-methylaniline (at $44 \%$ conversion). The addition of any bidentate PN ligand from the ligand library resulted in improved catalytic performance (Figure 7). Notably the addition of either the PNP-type 1a or the cyclohexanediamine-based $2 \mathbf{b}$ (at 1:1 L:M ratio, that is $2 \mathrm{P}: \mathrm{Ru}$ ) led to $N$-methylaniline in $>80 \%$ yield. In contrast, the monophosphine tested (3f) proved ineffective.
Table 2. Ru(II)-catalyzed benzylations of amines using method A: reaction scope. ${ }^{[a, b]}$

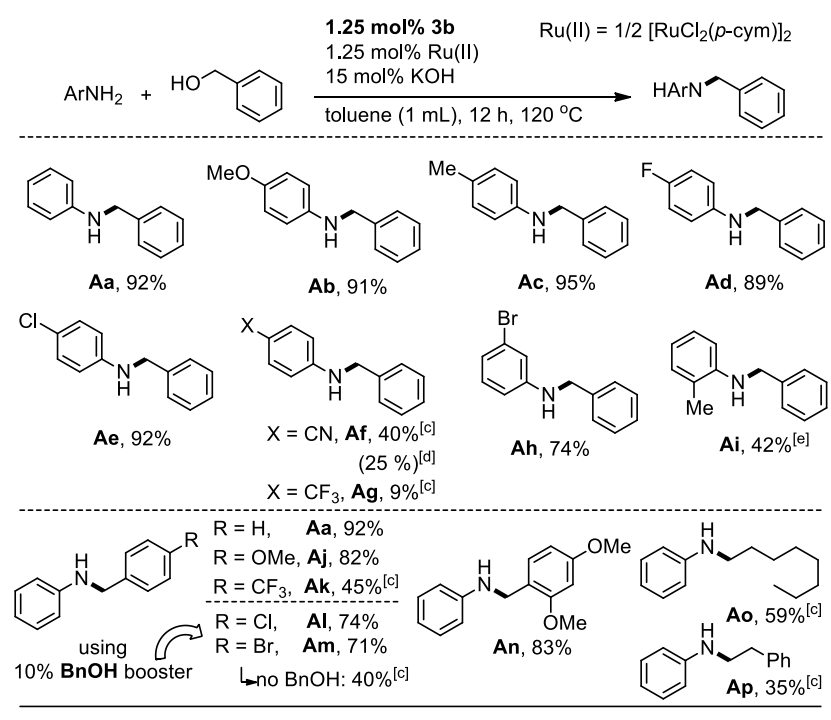

[a] In $15 \mathrm{~mL}$ tubes; [b] Yields of isolated material. [c] Corrected \%GC yields; ${ }^{[\mathrm{d}]}{ }^{\%} \mathrm{GC}$ yield of imine; ${ }^{[\mathrm{e}]}$ at $135{ }^{\circ} \mathrm{C}$.

Although the reaction tubes were heated by an $\mathrm{Al}$ block kept at $120^{\circ} \mathrm{C}$, a thermometer placed inside the $\mathrm{MeOH}$ solution in the closed reaction tube showed the internal temperature to be $76{ }^{\circ} \mathrm{C}, i$. $e$. approximately $11^{\circ} \mathrm{C}$ above the boiling point of $\mathrm{MeOH}$ at $1 \mathrm{~atm}$. This "overheating" proved crucial, as reducing the temperature of the heating block to $100{ }^{\circ} \mathrm{C}$ resulted in a drop in internal temperature to 68 ${ }^{\circ} \mathrm{C}$ and in yield to $63 \%$ (Table 3, also see Supporting Info).

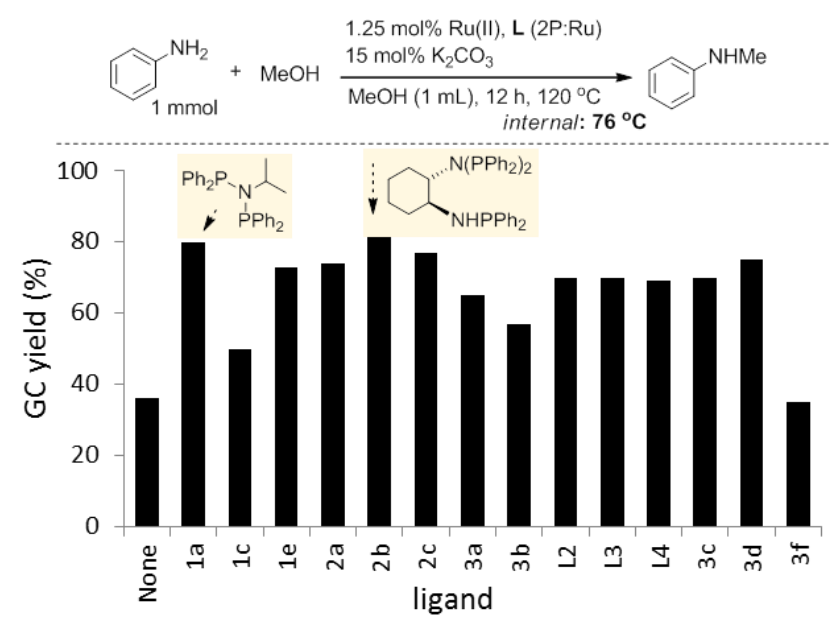

Figure 7. Screening of $\mathrm{PN}$ ligands in standard $\mathrm{PhNH}_{2-}$ methylation reaction in neat $\mathrm{MeOH}$. \%GC yield vs. mesitylene (average from at least two separate runs).

Considering the ease of preparation of $\mathbf{1 a}$, this ligand was applied to subsequent aniline $N$-alkylation reactions using aliphatic alcohols (method B). Indeed, by using $1.25 \mathrm{~mol} \%$ of the $\mathrm{Ru}(\mathrm{II}) / \mathbf{1 a}$ catalyst system several anilines bearing electron-donating and 
electron-withdrawing groups were successfully methylated (Table 3, Bb-Bd). For example, 4-chloro$\mathrm{N}$-methylaniline, Bd, is isolated in $75 \%$ yield using these conditions. Furthermore, the use of EtOH in place of $\mathrm{MeOH}$ produced the corresponding $\mathrm{N}$ ethylaniline derivatives Be-Bh.

As a test of catalyst utility, the $3 \mathbf{b} / \mathrm{Ru}(\mathrm{II})$ system was applied to the synthesis of $N$ alkylaminoferrocenes. Our interest stemmed from the promise shown by aminoferrocenes as prodrug candidates, including their toxicity in human promyelocytic leukemia (HL-60) and human glioblastoma-astrocytoma (U373). ${ }^{[22]}$

Table 3. $\mathrm{Ru}(\mathrm{II})$-catalyzed alkylations of anilines by method B. ${ }^{[a, b]}$

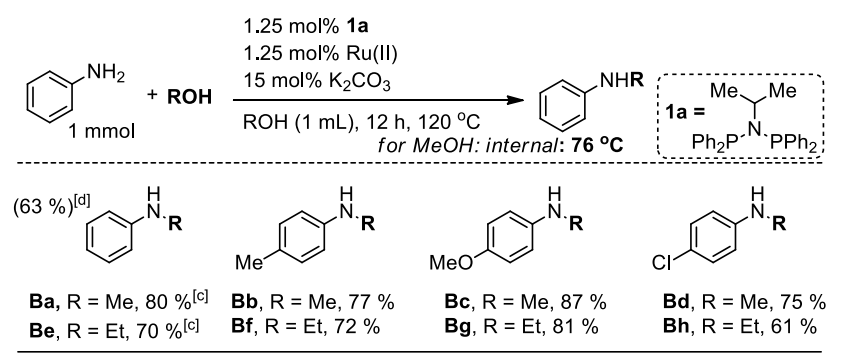

[a] In closed tubes [b] Yields of isolated product. ${ }^{[c]} \mathrm{GC}$ yields $v s$. mesitylene as int. standard (average from at least two separate runs). ${ }^{\text {[d] }}$ External heating to $100^{\circ} \mathrm{C}$.

As a first step, the parent aminoferrocene was synthesized from iodoferrocene ${ }^{[23]}$ and $\mathrm{NH}_{3}(\mathrm{aq})$ in the presence of a $\mathrm{CuI}-\mathrm{Fe}_{2} \mathrm{O}_{3}$ catalyst, as described recently by Gasser et al. ${ }^{[24]}$ While the original protocol employed $\mathrm{NaOH}$ (2.3 equiv), in our hands omitting this base was beneficial, leading to partial suppression of the proto-deiodination side reaction and resulting in a $77 \%$ yield of aminoferrocene on a $3.5 \mathrm{mmol}$ scale (see Supporting Info). This primary amine underwent smooth coupling with both electron-rich and electron-poor benzyl alcohols (Table 4, Ca-Cc). In particular, even the less reactive para-trifluoromethyl benzyl alcohol is an effective benzylating agent in this case, leading to $70 \%$ yield of the target monobenzylation product Cc. Moreover, both the $N$-methylation and $N$-ethylation of aminoferrocene, using this time the $\mathrm{Ru}(\mathrm{II}) / \mathbf{1 a}$-based system, took place with $>80 \%$ yield. The high reactivity of aminoferrocene is consistent with the trend observed earlier, whereby the $\mathrm{N}$-alkylation is favored for electron-rich aromatic amines.

Table 4. Alkylation of aminoferrocene.

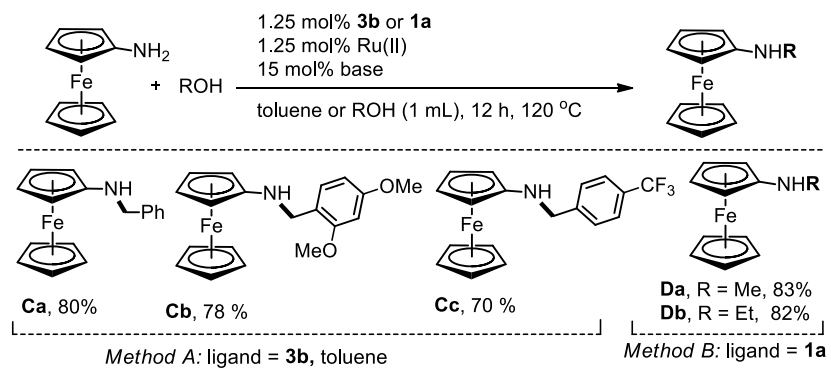

\section{Complex chemistry}

In light of the potent catalytic $N$-benzylation activity conferred by $\mathbf{3 b}$, the $\mathrm{Ru}(\mathrm{II})$ coordination chemistry of this ligand was studied. Despite the potential of $\mathbf{3 b}$ to act as a wide-angle bidentate ligand, exposing this bis-aminophosphine to $\left[\mathrm{RuCl}_{2}(p\right.$ cymene) $]_{2}$ in toluene inevitably led to the formation of the 1:2 3b:Ru complex 4. In the solid state ${ }^{[25]}$ each phosphorous is bound to a separate (cymene) $\mathrm{RuCl}_{2}$ unit (Scheme 4) thus completing the normal threelegged piano stool arrangement of an 18-e $\mathrm{Ru}(\mathrm{II})$ center $^{[26]}$ Indeed, while a $1: 1 \mathrm{3b}: \mathrm{Ru}$ ratio led to a mixture of $\mathbf{4}$ and free $\mathbf{3 b}$, at a $1: 2 \mathbf{3 b}: \mathrm{Ru}$ ratio the bimetallic $\mathbf{4}$ formed quantitatively within just $30 \mathrm{~min}$ ( $\delta 75.6 \mathrm{ppm}$ by $\left.{ }^{31} \mathrm{P}-\mathrm{NMR}\right)$ and crystallized from the reaction mixture in an $83 \%$ yield. In fact, even a new monometallic complex $\mathbf{5}$, obtained (along with $\mathbf{4}$ ) by switching to a toluene: $t \mathrm{BuOH}$ solvent mixture, was shown by both ${ }^{31} \mathrm{P}$ NMR and X-ray diffraction to contain the $\mathbf{3 b}$ unit with only one of the two phosphorous atoms bound to a (cymene) $\mathrm{RuCl}_{2}$ center. A glimpse into the potential of $\mathbf{3 b}$ as a bidentate ligand was gained by conducting the same reaction in $\mathrm{MeOH}$. Within $15 \mathrm{~min}$ reaction time, a yellow solution was observed and found to contain two new $\mathrm{Ru}-\mathrm{H}$ species, 6a and 6b. The hydridic ${ }^{1} \mathrm{H}-\mathrm{NMR}$ resonances (apparent $d q$ ) are observed at -5.72 and $7.11 \mathrm{ppm}$ respectively (see Supporting Info). The fact that these signals were still observed in $\mathrm{CD}_{3} \mathrm{OD}$ identifies $\mathbf{3 b}$ as the hydride source. For $\mathbf{6 a}$, the apparent $d q$ signals observed at $-5.72 \mathrm{ppm}$ (along with a matching set of four ${ }^{31} \mathrm{P}-\mathrm{NMR}$ resonances) was interpreted as an octahedral $\mathrm{Ru}(\mathrm{II})-\mathrm{H}$ center bound to four non-equivalent $\mathrm{P}$ atoms, likely from two chelating 3b units, one $\mathrm{CH}$-activated. Structural elucidation of $\mathbf{6 b}$ led to similar conclusions, and therefore we tentatively propose that these two intermediates are isomers. Overtime, as the intensity of these hydridic resonances diminished and the solution lightens, giving rise to a new distorted octahedral $\mathrm{Ru}$ (II)-H species 7. The X-ray structure of this 18-e species reveals a trans- $\mathrm{Cl}-\mathrm{Ru}-\mathrm{H}$ center supported by a dehydrogenated $\mathbf{3 b}$ unit, which now acts as a three-coordinate mer ligand through the two $\mathrm{P}$ atoms and the $\eta^{2}$-olefin moiety. A similar structure has already been reported by Gusev et al. ${ }^{[27]}$ The coordination sphere in $\mathbf{7}$ is completed by a $\mathrm{P}(\mathrm{OMe}) \mathrm{Ph}_{2}$ group, likely from the $\mathrm{P}-\mathrm{N}$ bond methanolysis $^{[28]}$ of a second $\mathbf{3 b}$ molecule. The hydridic resonance in 7 is found at $-13.58 \mathrm{ppm}$ (apparent $t d$ ), and the olefinic signals appear at $\delta 5.38$ $\left(d d,{ }^{3} J_{H P}=13.6,{ }^{3} J=8.5 \mathrm{~Hz}\right)$ and $4.91 \mathrm{ppm}\left(d d d,{ }^{3} \mathrm{~J}=\right.$ $8.5,4.7$ and $1.5 \mathrm{~Hz}$ ). Through a sequence of decoupling experiments, the ${ }^{31} \mathrm{P}-\mathrm{NMR}$ resonances at $\delta 35.5$ and $103.7 \mathrm{ppm}$ were assigned to $\mathrm{P}_{\mathrm{a}}$ and $\mathrm{P}_{\mathrm{b}}$ respectively. 


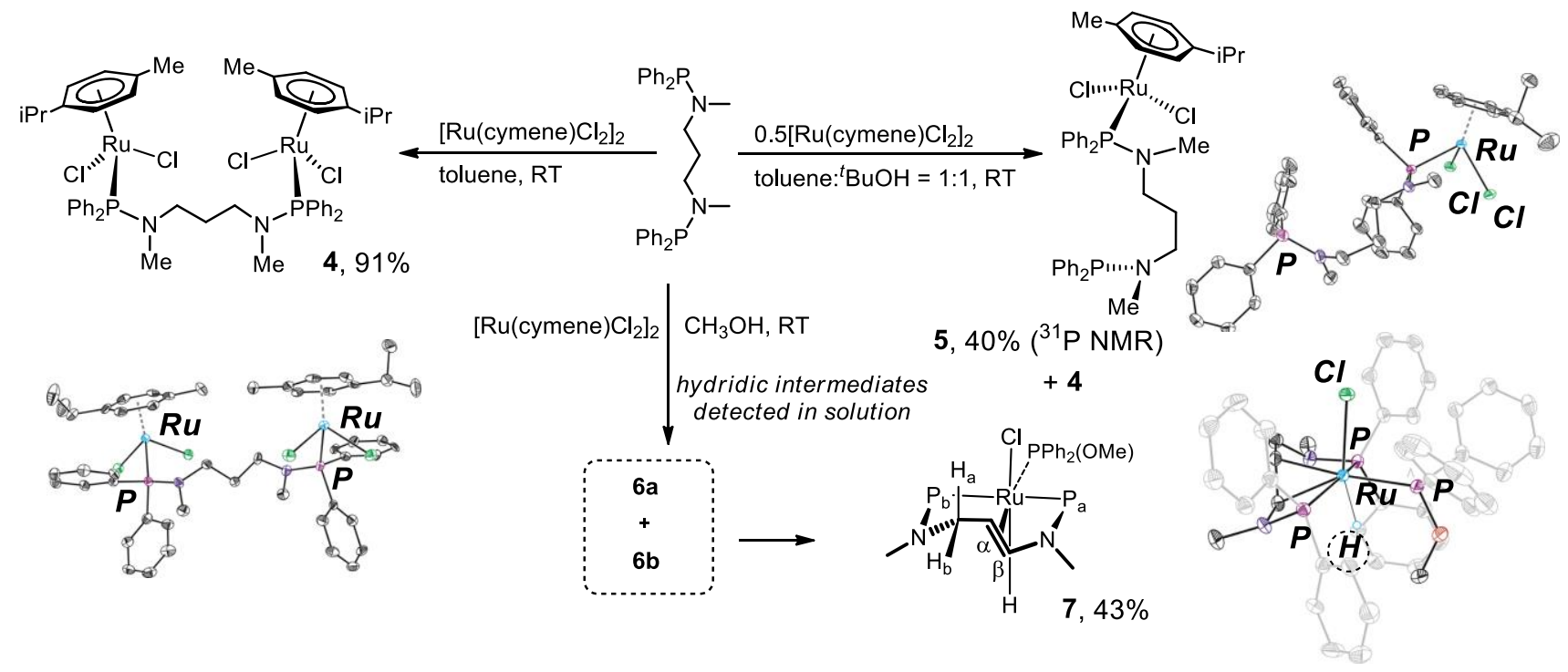

Scheme 4. Synthesis of complexes 4, 5 and 7, along with the corresponding solid state structures

The isolated $\mathbf{3 b} / \mathrm{Ru}(\mathrm{II})$ complexes $\mathbf{4}$ and $\mathbf{7}$ were tested in the model benzylation reaction of aniline. As seen in Table 5, while the $\mathrm{Ru}-\mathrm{H}$ species 7 proved to be a poor catalyst (entry 2), the performance of the bimetallic 4 (entry $3,84 \%$ ) is in line with that of a 1:2 ligand-to-metal mixture previously tested (see Table 1,4) Finally, the mixture of 4 (ca. $60 \%$ ) with 5 (ca. $40 \%$ ), as obtained from the reaction outlined in scheme 4, was as efficient as the 1:1 catalyst formed in situ (compare entry 1 and entry 4). ${ }^{[29]}$

Importantly, no hydridic resonances were detected when $\left[\mathrm{RuCl}_{2}(p \text {-cymene })\right]_{2}$ was exposed to ligands $\mathbf{3 a}$, 3c, $3 f$ and $\mathbf{L 3}$ in $\mathrm{CD}_{3} \mathrm{OD}$. Thus, although 7 is clearly a catalyst decomposition product, we believe that its formation, along with that of intermediates $\mathbf{6 a}$ and $\mathbf{6 b}$, signals that $\mathrm{CH}$ activation of the propylene backbone could play an important role in the catalytic cycle for the $3 \mathrm{~b} / \mathrm{Ru}(\mathrm{II})$ system (Scheme 5). Indeed, as seen above (Figure 4) poor catalytic performance was observed for $\mathbf{L 3}$ featuring a $\mathrm{CMe}_{2}$ at this key position.

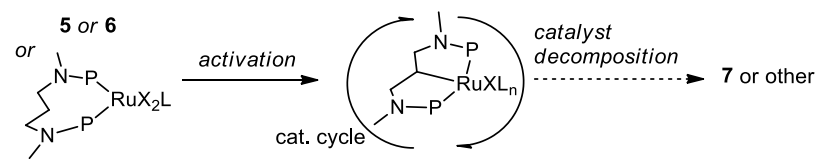

Scheme 5. A possible evolution of the $\mathbf{R u - 3 b}$ system.

Table 5. Testing of the isolated $\mathrm{Ru}(\mathrm{II})$ complexes of $\mathbf{3 b}$ in the benzylation of $\mathrm{PhNH}_{2}$ by BnOH. ${ }^{[a, b]}$

\begin{tabular}{llll}
\hline entry & Ru complex & $\%$ amine & $\%$ imine \\
\hline 1 & $\mathbf{3 b} /\left[\mathrm{RuCl}_{2}\right]($ cymene $\left.)\right]_{2}$ & $>99$ & 0 \\
2 & $\mathbf{7}$ & 40 & 35 \\
3 & $\mathbf{4}$ & 84 & 0 \\
4 & $\mathbf{4 / 5}$ mix & $>99$ & 0 \\
\hline
\end{tabular}

[a] In $15 \mathrm{~mL}$ closed tubes at $120{ }^{\circ} \mathrm{C}$; [b] \%GC yield $v s$. mesitylene (average from at least two separate runs)
As a final note, the ability of $\mathbf{3 b}$ to form wide bite angle chelates was confirmed through the synthesis of a $3 \mathbf{b}-\mathrm{Cr}(\mathrm{CO})_{4}$ complex prepared in $86 \%$ yield from $\mathrm{Cr}(\mathrm{CO})_{6}$. Its solid-state structure revealed a distorted octahedral geometry with the P-Cr-P chelate angle of $107^{\text {o[1b] }}$. For this species, at $298 \mathrm{~K}$ the lateral $\mathrm{NCH}_{2}$ groups of the propylene bridge are unobservable in the ${ }^{1} \mathrm{H}-\mathrm{NMR}$ spectrum due to a fluxional process $\left(\Delta \mathrm{G}^{\ddagger}=13.3 \mathrm{kcal} \mathrm{mol}^{-1}\right)$. At $328 \mathrm{~K}$ these appear as a single broad resonance at $\delta 3.40 \mathrm{ppm}$, which is consistent with an average $\mathrm{C}_{2 V}$ symmetry. We also note that heating two equiv. of $\mathrm{Cr}(\mathrm{CO})_{6}$ with $\mathbf{3 b}$ in toluene $\left(120{ }^{\circ} \mathrm{C}\right.$ for $\left.50 \mathrm{~h}\right)$ gives the bimetallic complex 9 in $51 \%$ yield.
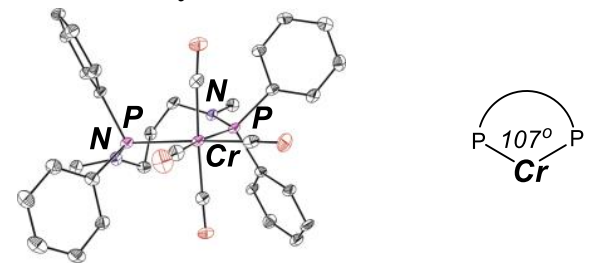

Figure 8. X-ray structure of 8. Selected bond lengths $(\AA)$ and angles $\left({ }^{\circ}\right)$ : $\mathrm{Cr}(1)-\mathrm{P}(1)$ 2.41, $\mathrm{Cr}(1)-\mathrm{P}(2) 2.41$ (1); $\mathrm{P}(1)$ Cr(1)-P(2) 107.0.

\section{Conclusions}

In summary, by screening our PN-ligand library in $\mathrm{Ru}(\mathrm{II})$-catalyzed $\mathrm{H}_{2}$-borrowing alkylation reactions of aromatic amines, we were able to discover and optimize two new high-yielding methods for synthesizing secondary aromatic amines.

Method A utilizes bidentate PN ligands from the PNR family with $\mathbf{3 b}$ giving the superlative selectivity and product yields for this process. Indeed the optimal combination of $\left[\mathrm{RuCl}_{2}(p \text {-cymene })\right]_{2} / \mathbf{3 b} / \mathrm{KOH}$ successfully catalyzes benzylations of a variety of aromatic amines, including aminoferrocene. 
Nonetheless this method does have its limitations and in fact only works effectively for benzylation reactions. Thus a second method (method B) was developed to overcome this initial restriction.

Method $B$ takes advantage of ligands from a different subfamily with the PNP derivatives giving the best performances. More specifically ligands 1a and $\mathbf{2 b}$ produce the highest yields of desired secondary amines. Moreover the alcohol serves not only as the alkylating agent but also as the reaction solvent in this methodology.

Noteworthy is that the two methods profit from different ligand structures. This fact demonstrates the importance of rapid ligand synthesis for such screening methodologies. In a more general sense taking advantage of facile PN bond formations for parallel screening of ligand sets is a powerful tool for quick discover and optimization of new reaction methodologies. In this context we are currently studying other processes in which this simplistic connection can be an asset.

\section{Experimental Section}

Synthesis of ligand 3b. A solution of $N, N^{\prime}-$ dimethylpropylenediamine $(1.00 \mathrm{~mL}, 8.00 \mathrm{mmol})$ in toluene $(30 \mathrm{~mL})$ was treated with triethylamine $(2.50 \mathrm{~mL}$ $17.92 \mathrm{mmol}$ ) and the flask was cooled to $0{ }^{\circ} \mathrm{C}$ Chlorodiphenylphosphine $(2.95 \mathrm{~mL}, 15.95 \mathrm{mmol})$ was slowly added. Formation of a white salt was immediately observed. Once the addition was completed, the cold bath was removed. After stirring for $6 \mathrm{~h}$, the mixture was concentrated to $20 \mathrm{~mL}$ and filtered to separate the ammonium salt. On removal of volatiles under reduced pressure, 3b was recovered as a colorless oil (2.53 g, 5.38 mmol, 67\%). A higher purity was achieved by extracting the residue into hexane $(50 \mathrm{~mL})$, filtering, evaporating the solvent and further washing with degassed ethanol. ${ }^{1} \mathrm{H}$ NMR (400 MHz, $\left.\mathrm{CD}_{2} \mathrm{Cl}_{2}\right) \delta: 7.45-7.34(\mathrm{~m}, 20 \mathrm{H}, \mathrm{Ar}), 3.08$ $-3.02\left(\mathrm{~m}, 4 \mathrm{H}, \mathrm{NCH}_{2}\right), 2.49\left(\mathrm{~d},{ }^{3} J_{\mathrm{HP}}=6.1 \mathrm{~Hz}, 6 \mathrm{H}, \mathrm{NCH}_{3}\right)$, $1.73\left(\mathrm{p},{ }^{3} \mathrm{~J}=8.0 \mathrm{~Hz}, 2 \mathrm{H}, \mathrm{CH}_{2}\right) .{ }^{13} \mathrm{C} \mathrm{NMR} \mathrm{(100} \mathrm{MHz,}$ $\left.\mathrm{CDCl}_{3}\right) \delta: 139.5\left(\mathrm{~d},{ }^{1} J_{\mathrm{CP}}=14.7 \mathrm{~Hz}\right.$, ipso-Ar CP $), 132.1(\mathrm{~d}$, $\left.{ }^{2} J_{\mathrm{CP}}=19.5 \mathrm{~Hz}, o-\operatorname{Ar} \mathrm{CH}\right), 128.4(p-\mathrm{ArCH}), 128.2\left(\mathrm{~d},{ }^{3} J_{\mathrm{CP}}=\right.$ $5.7 \mathrm{~Hz}, m-\mathrm{ArCH}), 54.4\left(\mathrm{~d},{ }^{2} J_{\mathrm{CP}}=28.2 \mathrm{~Hz}, \mathrm{NCH}_{2}\right), 37.2(\mathrm{~d}$, $\left.{ }^{2} J_{\mathrm{CP}}=1.2 \mathrm{~Hz}, \mathrm{NCH} 3\right), 28.6\left(\mathrm{t},{ }^{3} J_{\mathrm{CP}}=5.9 \mathrm{~Hz}, \mathrm{CH}_{2}\right) .{ }^{31} \mathrm{P}$ NMR (161 MHz, $\left.\mathrm{CDCl}_{3}\right) \delta: 67.33$

Catalysis by $\mathrm{Ru}(\mathrm{II})-3 \mathrm{~b}$ : synthesis of $\boldsymbol{N}$-benzylaniline. In

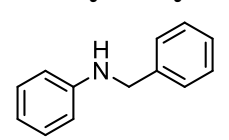
an argon-filled glovebox, an oven-dried screw-top reaction tube was charged with $\left[\mathrm{RuCl}_{2}(p \text {-cymene })\right]_{2}(3.8 \mathrm{mg}, 6.3 \mu \mathrm{mol}$, $1.25 \mathrm{~mol} \% \mathrm{Ru})$, the ligand $\mathbf{3 b}(5.9 \mathrm{mg}$, $12.5 \mu \mathrm{mol}, 1.25 \mathrm{~mol} \%)$, potassium hydroxide $(8.4 \mathrm{mg}, 0.15 \mathrm{mmol}, 15 \mathrm{~mol} \%)$ and toluene (1 $\mathrm{mL})$. Benzylalcohol $(109 \mu \mathrm{L}, 1.05 \mathrm{mmol})$ and aniline (92 $\mu \mathrm{L}, 1.0 \mathrm{mmol}$ ) were then added, the tube was sealed with a screw-cap septum and heated at $120{ }^{\circ} \mathrm{C}$ for $12 \mathrm{~h}$ with agitation. Column chromatography: silica gel, $\mathrm{R}_{\mathrm{f}}=0.45$ Hex:EtOAc, 9:1. Colorless oil (solidifies), yield: $169 \mathrm{mg}$, $0.92 \mathrm{mmol}, 92 \% .{ }^{1} \mathrm{H}$ NMR $\left(400 \mathrm{MHz}, \mathrm{CDCl}_{3}\right) \delta 7.47-7.24$ (m, 7H, Ar), 6.83-6.70 (m, 3H, Ar), $4.40\left(\mathrm{~s}, 2 \mathrm{H}, \mathrm{CH}_{2}\right), 4.08$ (s, 1H, NH).

Catalysis by Ru(II)-3b: synthesis of $N$-(4triflouromethyl)benzyl aminoferrocene. The compound

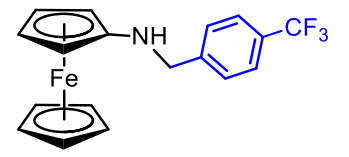
was prepared following the procedure described for aniline. Here, a mixture of aminoferrocene (100 $\mathrm{mg}, 0.5$ $\mathrm{mmol}$ ), trifluoromethylbenzylalcohol

(92 $\mathrm{mg}, 0.525)$ was exposed to $\left[\mathrm{RuCl}_{2}(p \text {-cymene) }]_{2}\right.$ (1.9 $\mathrm{mg}, 3.2 \mu \mathrm{mol}, 1.25 \mathrm{~mol} \% \mathrm{Ru})$, the ligand $\mathbf{3 b}(3.0 \mathrm{mg}, 6.3$ umol, $1.25 \mathrm{~mol} \%$ ), potassium hydroxide (4.2 $\mathrm{mg}, 0.08$ mmol, $15 \mathrm{~mol} \%)$ and toluene $(0.5 \mathrm{~mL})$. Column chromatography: silica gel, $\mathrm{R}_{\mathrm{f}}=0.44$ for Hex:EtOAc, 10:1). Red solid, yield: $124 \mathrm{mg}, 0.35 \mathrm{mmol}, 70 \%$. ${ }^{1} \mathrm{H}$ NMR $\left(400 \mathrm{MHz} \mathrm{CDCl}_{3}\right) \delta 7.62-7.59(\mathrm{~m}, 2 \mathrm{H}, \mathrm{Ar}), 7.53-7.50$ $(\mathrm{m}, 2 \mathrm{H}, \mathrm{Ar}), 4.23\left(\mathrm{~d},{ }^{3} \mathrm{~J}=5.8 \mathrm{~Hz}, 2 \mathrm{H}, \mathrm{CH}_{2}\right), 4.17(\mathrm{~s}, 5 \mathrm{H}$, $\left.\mathrm{C}_{5} \mathrm{H}_{5}\right), 3.88(\mathrm{~s}, 4 \mathrm{H}, \mathrm{Cp} \mathrm{CH}), 2.73\left(\mathrm{t},{ }^{3} \mathrm{~J}=5.0 \mathrm{~Hz}, 1 \mathrm{H}, \mathrm{NH}\right)$. ${ }^{13} \mathrm{C}$ NMR $\left(101 \mathrm{MHz}, \mathrm{CDCl}_{3}\right) \delta 144.1$ (Ar, ipso-CCH $129.6\left(\mathrm{q},{ }^{2} J_{C F}=32.4 \mathrm{~Hz}\right.$, ipso- $\left.-\mathrm{CF}_{3}\right), 128.0(\mathrm{Ar} \mathrm{CH}), 125.6$ $\left(\mathrm{q},{ }^{3} J_{C F}=3.8 \mathrm{~Hz}, \operatorname{Ar} \mathrm{CH}\right), 124.3\left(\mathrm{q}, J_{C F}=272 \mathrm{~Hz}, \mathrm{CF}_{3}\right)$, 110.5 (ipso-CpN), $68.2\left(\mathrm{Cp}, \mathrm{C}_{5} \mathrm{H}_{5}\right), 63.3(\mathrm{Cp} \mathrm{CH}), 56.2$ $(\mathrm{Cp} \mathrm{CH}), 51.7\left(\mathrm{CH}_{2}\right)$. HRMS $\left(\mathrm{ESI}^{+}\right) \mathrm{m} / \mathrm{z}$ calcd for $\mathrm{C}_{18} \mathrm{H}_{16} \mathrm{~F}_{3} \mathrm{FeN}[\mathrm{M}]^{+}$359.0579, found: 359.0582 .

\section{Acknowledgements}

We thank Dr. Andrew Chapman for his generous help at the early stages of this project. L. M. Broomfield thanks the CELLEX Foundation for a post-doctoral contract. This work was financed through grants from ICIQ, MINECO (CTQ2013-46705-R and 2014-2018 Severo Ochoa Excellence Accreditation SEV-20130319) and the Generalitat de Catalunya (2014 SGR 1192). Financial support from CELLEX Foundation through the CELLEX-ICIQ High Throughput Experimentation platform is gratefully acknowledged.

\section{References}

[1] See the following list for some examples: a) M. E van der Boom, D. Milstein, Chem. Rev. 2003, 103, 17591792; b) P. W. N. M. van Leeuwen, P. C. J. Kamer, J. N. H. Reek, P. Dierkes, Chem. Rev. 2000, 100, 27412769; c) K. H. Shaughnessy, P. Kim, J. F. Hartwig, J. Am. Chem. Soc. 1999, 121, 2123-2132, d) C. A. Tollman, Chem. Rev. 1977, 77, 313-348.

[2] a) A. Carter, S. A. Cohen, N. A. Cooley, A. Murphy, J. Scutt, D. F. Wass, Chem Commun., 2002, 858-859; b) D. F. Wass, BP Chemicals Ltd, WO 02/04119, 2002; c) A. Bollmann, K. Blann, J. T. Dixon, F. M. Hess, E. Killian, H. Maumela, D. S. McGuinness, D. H. Morgon, A. Neveling, S. Otto, M. Overett, A. M. Z Slawin, P. Wassercheid, S. Kuhlmann, J. Am. Chem. Soc. 2004, 126, 14712-14713; (d) S. Kuhlmann, K. Blann, A. Bollmann, J. T. Dixon, E. Killian, M. C. Maumela, H. Maumela, D. H. Morgan, M. Pretorius, N. Taccardi, P. Wasserscheid, J. Catal., 2007, 245, $279-$ 284; e) T. Agapie, Coord. Chem. Rev. 2011, 255, 861880 and references therein; f) D. S. McGuinness, Chem.Rev. 2011, 111, 2321 - 2341 and references therein; g) Y. Shaikh, K. Albahily, M. Sutcliffe, V. Fomitcheva, S. Gambarotta, I. Korobkov, R. Duchateau, Angew. Chem. Int. Ed. 2012, 51, 13661369.

[3] a) D. J. Jones, V. C. Gibson, S. M. Green, P. J. Maddox, A. J. P. White, D. J. Williams, J. Am. Chem. Soc. 2005, 127, 11037-11046; b) T. R. Boussie, G. M. Diamond, C. Goh, K. A. Hall, A. M. Lapointe, M. K. Leclerc, C. Lund, V. Murphy, Symyx Technologies, Inc., USA, W2002038628, 2002; c) D. J. Jones, V. C. Gibson, S. M. Green, P. J. Maddox, Chem. Commun. 2002, 10381039 d) J. Tian, G. W. Coates, Angew. Chem., Int. Ed. 2000, 39, 3626-3629.

[4] a) S. M. Aucott, M. L. Clarke, A. M. Z. Slawina, J. D. Woollins, J. Chem. Soc., Dalton Trans. 2001, 972-976; b) for a recent review on aminophosphines as synthons 
and ligands, see: J. Gopalakrishnan, Appl. Organomet. Chem. 2009, 23, 291-318.

[5] a) E. Tomás-Mendivil, R. García-Alvarez, C. Vidal, P. Crochet, V. Cadierno, ACS Catal. 2014, 4, 1901-1910; b) R. García-Alvarez, P. Crochet, V. Cadierno, Green Chem. 2013, 15, 46-66; c) R. García-Alvarez, J. Díez, P. Crochet, V. Cadierno, Organometallics 2011, 30, 3908-3910.

[6] M. Aydemir, A. Baysal, Polyhedron 2010, 29, 12191224.

[7] M. D. Levin, F. D. Toste, Angew. Chem. Int. Ed. 2014, 53, 6211-6215.

[8] a) S. R. Harutyunyan, T. den Hartog, K. Geurts, A. J. Minnaard, B. L. Feringa, Chem. Rev., 2008, 108, 28242852; b) A. Alexakis, J. E. Backvall, N. Krause, O. Pàmies, M. Diéguez, Chem. Rev., 2008, 108, 27962823.

[9] a) Y. Ju, R. S. Varma, Green Chem. 2004, 6, 219-221; b) J. Clayden, N. Greeves, S. Warren, P. Wothers, Organic Chemistry, Oxford University Press: USA, 2001; c) R. N. Salvatore, C. H. Yoon, K. W. Jung, Tetrahedron 2001, 57, 7785-7811; d) C. Grimm, O. Hamed, T. L. Vigo, N. R. Bertoniere, J. Org. Chem. 2000, 65, 9234-9237; e) K. Mohri, K. Suzuki, M. Usui, K. Isobe, Y. Tsuda, Chem. Pharm. Bull. 1995, 43, 159161; f) A. Pelter, K. Smith, H. C. Brown, Borane Reagents, Academic Press: London, 1988; g) $\mathrm{H}$. Yamamoto, K. Maruoka, J. Org. Chem. 1980, 45, 2739-2740.

[10] a) F. Valot, F. Fache, R. Jacquot, M. Spagnol, M. Lemaire, Tetrahedron Lett. 1999, 40, 3689-3692; b) S. Narayanan, B. P. Prasad, J. Chem. Soc. Chem. Commun. 1992, 1204-1205; c) H. Matsuhashi, K. Arata, Bull. Chem. Soc. Jpn. 1991, 64, 2605-2606.

[11] a) C. Chiappe, D. Pieraccini, Green Chem. 2003, 5, 193-197; b) R. N. Salvatore, A. S. Nagle, K. W. Jung, J. Org. Chem. 2002, 67, 674-683.

[12] a) G. E. Dobereiner, R. H. Crabtree, Chem. Rev. 2010, 110, 681-703; b) G. Guillena, D. J. Ramon, M. Yus, Chem. Rev. 2010, 110, 1611-1641; c) T. D. Nixon, M. K. Whittlesey, J. M. J. Williams, Dalton Trans. 2009, 753-762; d) S. Bähn, A. Tillack, S. Imm, K. Mevius, D. Michalik, D. Hollmann, L. Neubert, M. Beller, ChemSusChem. 2009, 2, 551-557; e) B. Blank, S. Michlik, R. Kempe, Adv. Synth. Catal. 2009, 351, 2903-2911; f) S. Liu, M. Rebros, G. Stephens, A. C. Marr, Chem. Commun. 2009, 2308-2310; g) B. Blank, M. Madalska, R. Kempe, Adv. Synth. Catal. 2008, 350, 749-758; h) K.-I. Fujita, Y. Enoki, R. Yamaguchi, Tetrahedron 2008, 64, 1943-1954; i) M. H. S. A. Hamid, P. A. Slatford, J. M. J. Williams, Adv. Synth. Catal. 2007, 349, 1555-1575; j) A. Tillack, D. Hollmann, D. Michalik, M. Beller, Tetrahedron Lett. 2006, 47, 8881-8885; k) K-I. Fujita, T. Fujii, R. Yamaguchi, Org. Lett. 2004, 6, 3525-3528; 1) C. Gunanathan, D. Milstein, Science 2013, 341, 249-260.

[13] a) W. M. J. Ma, T. D. James, J. M. J. Williams, Org. Lett. 2013, 15, 4850-4853; b) A. J. A. Watson, J. M. J. Williams, Science 2010, 329, 635-636.

[14] a) A. J. A. Watson, A. C. Maxwell, J. M. J. Williams, J. Org. Chem. 2011, 76, 2328-2331; b) M. H. S. A.
Hamid, C. L. Allen, G. W. Lamb, A. C. Maxwell, H. C. Maytum, A. J. A. Watson, J. M. J. Williams, J. Am. Chem. Soc. 2009, 131, 1766-1774; c) M. H. S. A. Hamid, J. M. J. Williams, Chem. Commun. 2007, 725727.

[15] W. Baumann, A. Spannenberg, J. Pfeffer, T. Haas, A. Köckritz, A. Martin, J. Deutsch, Chem. Eur. J., 2013, 19, 17702-17706.

[16] G. R. M. Dowson, M. F. Haddow, J. Lee, R. L. Wingad, D. F. Wass, Angew. Chem. Int. Ed. 2013, 52, 9005-9008.

[17] a) R. H. Contreras, J. E. Peralta, Prog. Nucl. Mag. Res. $S P .2000,37,321-425$ b) R. J. Cross, T. H. Green, R. Keat, J. Chem. Soc., Dalton Trans. 1976, 1424-1428.

[18] a) W. H. Hersh, S. T. Lam, D. J. Moskovic, A. J. Panagiotakis. J. Org. Chem. 2012, 77, 4968-4979; b) R. Ballesteros-Garrido, L. Bonnafoux, F. Blanco, R. Ballesteros, F. R. Lerroux, B. Abarca, F. Colobert, I. Alkorta, J. Elguero, Dalton Trans. 2011, 40, $1387-$ 1395 ; c) L. D. Quin, K. C. Caster, J. C. Kisalus, K. A. Mesch, J. Am. Chem. Soc. 1984, 106, 7021-7032; d) L. D. Quin, M. J. Gallagher, G. T. Cunkle, D. B. Chesnut, J. Am. Chem. Soc. 1980, 102, 3136 - 3143.

[19] S. Agrawal, M. Lenormand, B. Martín-Matute, Org. Lett. 2012, 14, 1456-1459.

[20] K. Fujita, Z. Z. Li, N. Ozeki, R. Yamaguchi, Tetrahedron Lett. 2003, 44, 2687-2690.

[21] Interestingly para-CN does not deactivate the catalyst and total product yields formed from the standard aniline are high (>90\%). Nonetheless, the reduction of the cyano group and its subsequent alkylation reduce the efficiency of rehydrogenation processes. On the other hand, 4-triflouromethylaniline does deactivate the catalyst.

[22] a) P. Marzenell, H. Hagen, L. Sellner, T. Zenz, R. Grinyte, V. Pavlov, S. Daum, A. Mokhir, J. Med. Chem. 2013, 56, 6935-6944; b) H. Hagen, P. Marzenell, E. Jentzsch, F. Wenz, M. R. Veldwijk, A. Mokhir, J. Med. Chem. 2012, 55, 924- 934.

[23] a) M. S. Inkpen, S. Du, M. Driver. T. Albrecht, N. J. Long, Dalton Trans. 2013, 42, 2813-2816; b) J. C. Goeltz, C. P. Kubiak, Organometallics 2011, 30, 39083910 .

[24] a) A. Leonidova, T. Joshi, D. Nipkow. A. Frei, J.-E. Penner, S. Konatschnig, M. Patra, G. Gasser, Organometallics 2013, 32, 2037-2040.

[25] CCDC-1428556, CCDC-1428557, CCDC-1428558, CCDC-1428559 and CCDC-1428560 contain the supplementary crystallographic data for this paper. These data can be obtained free of charge from The Cambridge Crystallographic Data Centre via www.ccdc.cam.ac.uk/data_request/cif.

[26] a) J. H. Nelson, H. D. Hansen, Organometallics 2000, 19, 4740-4755; b) C. Moise, P. Le Gendre, P. J. Richard, J. Organomet. Chem. 2000, 605, 151-156; c) I. Moldes, E. Encarnación, J. Ros, A. Alvarez-Larena, J. F. Piniella, J. Organomet. Chem., 1998, 566, 165-174; d) M. R. J. Elsegood, D. A. Tocher, Polyhedron 1995, 14, 3147-3156 
[27] a) V. F. Kuznetsov, A. R. Kamaluddin, A. J. Lough, D. G. Gusev, J. Am. Chem. Soc. 2006, 128, 14388-14396; b) D. G. Gusev, A. J. Lough, Organometallics 2002, 21, 5091-5099; c) D. G. Gusev, A. J. Lough, Organometallics 2002, 21, 2601-2603.

[28] a) K. G. Gaw, M. B. Smith, J. B. Wright, A. M. Z. Slawin, S. J. Coles, M. B. Hursthouse, G. J. Tizzard, J. Organomet. Chem. 2012, 699, 39-47; b) J. Gopalakrishnan. Appl. Organometal. Chem. 2009, 23, 291-318; c) W. Ong, A. B. Beeler, S. Kesavan, J. S. Panek, J. A. Porco, Angew. Chem. Int. Ed. 2007, 46, 7470-7472; d) S. Priya, M. S. Balakrishna, J. T. Mague, S. M. Mobin, Inorg. Chem. 2003, 39, 1272-1281; e) P.
W. Dyer, J. Fawcett, M. J. Hanton, R. D. W. Kemmitt, R. Padda, N. Singh, Dalton Trans. 2003, 104-113; f) V. Chandrasekhar, S. Kingsley, A. Vij, K. C. Lam, A. L. Rheingold, Inorg. Chem. 2000, 39, 3238-3242; g) S. Kingsley, A. Vij, V. Chandrasekhar, Inorg. Chem. 2001, 40, 6057-6060.

[29] As suggested by a referee, an attempt was made to carry out the reaction using a mixture $6 \mathbf{a}+\mathbf{6 b}$. Some activity was observed, but the results have been inconclusive, giving a reasonable activity (80\%) but a selectivity only slightly better than for complex 7 . 


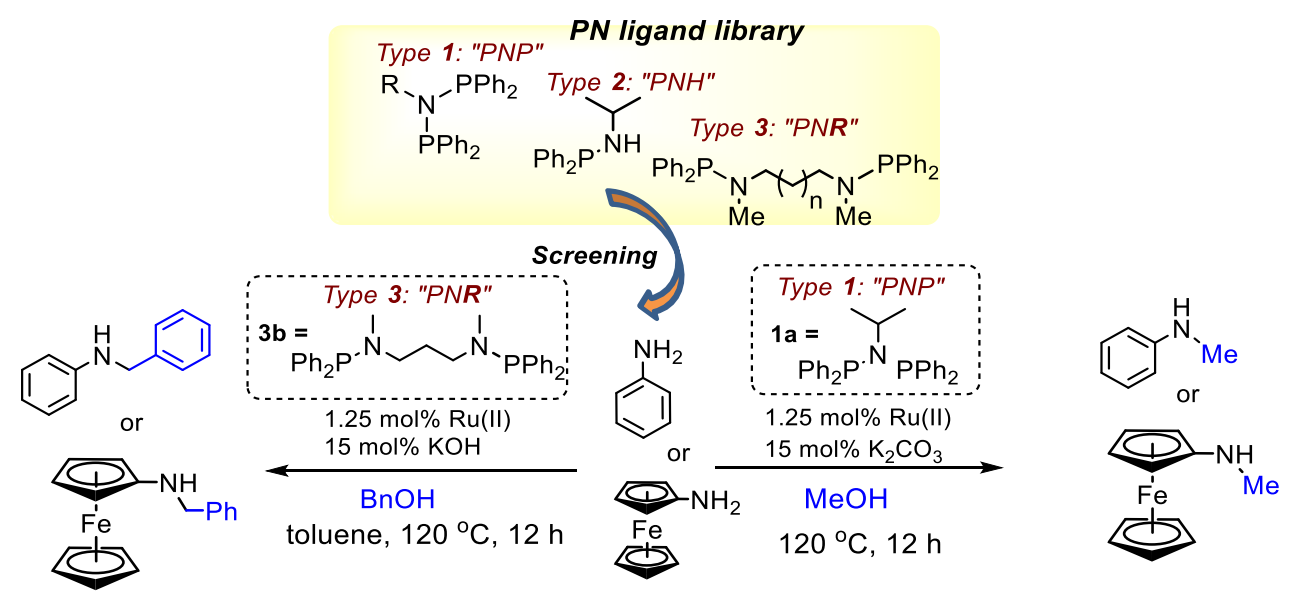

Aiming to accelerate catalyst discovery, we show that large families of bis- and monodentate aminophosphine ligands can be generated rapidly in one step from commercial amines. One such family is shown to produce a Ru catalyst, based on $N, N^{\prime}$-dimethyl- $N, N^{\prime}$-bis(diphenylphosphine) propylenediamine, highly active in alcohol amination. The best system was further investigated in terms of substrate scope and several relevant $\mathrm{Ru}$ complexes were isolated and characterized. The flexibility of the approach is further seen in the identification of a different catalyst system specific for the $\mathrm{MeOH}$ and $\mathrm{EtOH}$ electrophiles. 